\title{
Age- and Dietary-Related Distributions of Hepatic Arachidonic and Docosahexaenoic Acid in Early Infancy
}

\author{
JAMES FARQUHARSON, E. CHERRY JAMIESON, ROBERT W. LOGAN, W. J. AINSLIE PATRICK, \\ ALLAN G. HOWATSON, AND FORRESTER COCKBURN \\ Department of Biochemistry [J.F., E.C.J., R.W. L.], Department of Pathology [W.J.A.P., A.G.H.], and \\ Department of Child Health [F.C.], Royal Hospital for Sick Children, Yorkhill, Glasgow G3 8SJ, Scotland
}

\begin{abstract}
A dietary-related deficiency of docosahexaenoic acid [C22:6(n-3)] in infant cerebral cortex has been identified. Absence or very low rates of hepatic synthesis from the essential fatty acid precursor, $\alpha$-linolenic acid [C18:3(n-3)], in early life may have been a contributory factor. We have analyzed liver total lipid fatty acid compositions in 27 term (37-42 wk gestation) and 4 preterm (30-33 wk gestation) infants who died within the first $6 \mathrm{mo}$ of life from sudden infant death syndrome. The infants were fed exclusively either human or formula milks. Formula-fed infants were subdivided into two groups, one receiving SMA milk with an $\alpha$-linolenic acid content at $1.5 \%$ of total fatty acids and the other a composite group fed milks with low $\alpha$-linolenic acid concentrations $(<0.1 \%$ to $0.4 \%)$. The hepatic content of arachidonic acid $[\mathrm{C} 20: 4(n-6)]$ and docosahexaenoic acid was generally lower in both formula-fed groups than in
\end{abstract}

ABSTRACT the human milk-fed group. The age-related distributions of docosahexaenoic acid showed that coincident minimum levels were present in both formula groups in the third month of life. This may indicate that the hepatic enzymes involved in the final stage ( $\Delta 4$-desaturation) conversion of $\alpha$-linolenic acid to docosahexaenoic acid could be inactive in the first months of life. Emphasis must be on provision of preformed dietary docosahexaenoic acid and possibly arachidonic acid as well as their essential fatty acid precursors, to both term and preterm infants for at least the first 16 wk of life. (Pediatr Res 38: 361-365, 1995)

\author{
DHA, docosahexaenoic acid \\ Abbreviations \\ AA, arachidonic acid \\ LCPUFA, long-chain polyunsaturated fatty acid
}

It has now been established that the LCPUFA DHA [C22:6(n-3)] and AA [C20:4(n-6)] should be supplied in formula milks fed to both term and preterm infants (1-5). What is uncertain, however, is the optimum duration for such supplementation. To estimate this would probably require us to define the age at which DHA and AA are synthesized in the infant liver by enzymatic conversion of their essential fatty acid precursors $\alpha$-linolenic [C18:3(n-3)] and linoleic acid [C18:2(n$6)$ ], respectively. Desaturation of these essential fatty acids is performed in a series of reactions located primarily in the hepatic microsomes of the endoplasmic reticulum. Conversion of $\alpha$-linolenic acid to DHA and linoleic acid to AA proceeds via successive desaturation and elongation reactions involving $\Delta 6$ - and $\Delta 5$-desaturase enzymes and $\Delta 4$-desaturation, with in vitro studies initially implicating $\Delta 6$-desaturase as the ratelimiting step (6). Measurement of the $\Delta 6$ - and $\Delta 5$-desaturases has been made in human tissue $(7,8)$, although most research

Received July 27, 1994; accepted March 20, 1995.

Correspondence and reprint requests: Dr. James Farquharson, Department of Biochemistry, Royal Hospital for Sick Children, Yorkhill, Glasgow G3 8SJ, Scotland. in this area has inevitably been confined to animal models $(9-12)$. We considered that as the complex multistage enzyme systems involved are unstable and rapidly inactivated in biopsy material (7), analysis of the hepatic LCPUFA products of these reactions might be more informative as to their overall in vivo activities $(13,14)$. In the rat administered radiolabeled linoleic and $\alpha$-linolenic acids have been subsequently identified in liver triglyceride and phospholipid fractions as both the parent and LCPUFA derivative (15). Any investigation of liver fatty acids would therefore need to take into account this widespread distribution of LCPUFA. However, no in vitro enzymatic assays will ever adequately represent the complexity of lipid interactions associated with the intact liver. The most recently published results for human neonatal hepatic microsomal desaturases (7) appear to indicate enzyme activities of an order that may be sufficient to provide a limited supply of both DHA and AA to neuronal tissue to enable repair and renewal but inadequate for the large amounts of these LCPUFA required by the rapidly growing brain during this early period of development $(2,16,17)$. In addition, as the hepatic desaturase activities are known to be dependent on initial substrate concentrations, we recognized that examination of tissue from infants having 
received a diet low in $\alpha$-linolenic acid may be particularly informative.

\section{METHODS}

The population investigated were infants diagnosed as sudden infant death syndrome by experienced pediatric pathologists. They were aged less than 6 mo and had lived in the Greater Glasgow Health Board area during the period of $6 \mathrm{y}$ from May 1987 to July 1993. Liver specimens were taken at necropsy from the right lobe and stored at $-60^{\circ} \mathrm{C}$ before analysis. Pathologic examination excluded any specimens in which significant fatty infiltration or deposition had been evident. Liver samples from 27 term infants were subsequently assigned to one of three feeding groups, the prerequisite of which being that the infant had received exclusively a milk diet of fatty acid composition defined by that group. The ageequivalent dietary group compositions and details are provided in Table 1. Group 1 infants were breast fed, receiving both LCPUFA and their essential fatty acid precursors. Group 2 were fed exclusively SMA formula devoid of LCPUFA (C20 and $\mathrm{C} 22$ ) but with an $\alpha$-linolenic acid content of $1.5 \%$ of total fatty acids, a composition similar to that found in most U.S. and European formulations. Group 3 infants had been fed formulas both lacking in these LCPUFA but also with low concentrations of $\alpha$-linolenic acid varying between $<0.1 \%$ and $0.4 \%$ of total fatty acids, which were unique to the milks outlined in Table 1. In spite of the extended collection period, few significant changes occurred in the lipid contents of the formula milks in respect of the nonessential saturated and mono-unsaturated fatty acids. During this time formula linoleic acid contents remained relatively constant at between 12 to
$18 \%$ of total fatty acids. Liver tissue from two preterm infants ( 30 and $32 \mathrm{wk}$ of gestation) aged 10 and $17 \mathrm{wk}$, respectively, fed diet 2 and a further two 13-wk-old preterm infants (31 and 33 wk of gestation) fed diet 3 were examined.

Tissue analysis. On thawing, core samples (250-500 mg) were taken from the liver, and extraneous blood was removed by washing with distilled water. On drying, the tissue was weighed, lipid extraction was performed as previously described (1), and the weight of lipid isolated was noted to calculate the percentage of recovery. Fatty acids were derivatized in 2-mL boron trifluoride:methanol (14\% wt/vol) to which $200 \mu \mathrm{L}$ of chloroform had been added, enabling the phospholipids, triglycerides, and cholesterol esters to be transesterified in a one-step procedure to give fatty acid extracts of total hepatic lipid. The derivatized fatty acid methyl esters were separated and identified by gas chromatography (1).

To correct for the non-fatty acid component of these lipids toward recoveries, extracts were assayed for total cholesterol (cholesterol 352-20, Sigma Chemical Co., UK), triglyceride glycerol (triglyceride UV, 334-A, Sigma Chemical Co., UK) and phospholipid choline phosphate (18). To verify homogeneous distribution of liver fatty acids tissue samples were assayed from two different parts of each specimen. The assessment of stability of hepatic fatty acids with storage of tissue at $-60^{\circ} \mathrm{C}$ was evaluated by reassaying specimens after intervals of between 6 mo and $1 \mathrm{y}$.

\section{STATISTICAL ANALYSIS}

The 10 most abundant fatty acids accounted for $>98 \%$ of total lipid fatty acids (Table 2). Results were expressed, with reference to lipid recovery, as $\mathrm{g} / \mathrm{kg}$ wet tissue. In all groups

Table 1. Term infant details, dietary groups, and milk fatty acid compositions

\begin{tabular}{|c|c|c|c|c|}
\hline \multirow[b]{3}{*}{ Diet } & & \multicolumn{3}{|c|}{ Group } \\
\hline & & 1 & 2 & 3 \\
\hline & & $\mathrm{HM}^{*}$ & SMA† & MIX \\
\hline \multicolumn{5}{|l|}{ Infant data§ } \\
\hline Birthweight (g) & & $3380(492)$ & $3133(365)$ & $3011(384)$ \\
\hline Liver weight (g) & & $201(37)$ & $205(41)$ & $191(71)$ \\
\hline Gestational age (wk) & & $40.6(1.2)$ & $39.8(1.1)$ & $39.4(1.5)$ \\
\hline Age (wk) & & 11.3 & 11.6 & 12.9 \\
\hline Age range (wk) & & $2-21$ & $2-22$ & $4-21$ \\
\hline Male:female ratio & & $2: 5$ & $7: 4$ & $7: 2$ \\
\hline \multicolumn{5}{|l|}{ Milk fatty acid ranges } \\
\hline Myristic & $\mathrm{C} 14: 0$ & $3.8-11.5$ & $6.0-11.4$ & $5.2-12.5$ \\
\hline Palmitic & $\mathrm{C} 16: 0$ & $20.3-29.0$ & $13.0-22.8$ & $12.4-22.8$ \\
\hline Palmitoleic & C16:1 (n-7) & $1.5-3.9$ & $1.1-1.6$ & $0.5-0.8$ \\
\hline Stearic & C18:0 & $4.6-9.5$ & $3.9-8.2$ & $3.6-6.5$ \\
\hline Oleic & C18:1 (n-9) & $31.3-43.4$ & $34.0-36.6$ & $29.5-46.7$ \\
\hline Linoleic & $\mathrm{C} 18: 2(n-6)$ & $6.3-15.7$ & $16.0-17.8$ & $12.1-15.5$ \\
\hline$\alpha$-linolenic & C18:3 $(n-3)$ & $0.5-1.2$ & $1.4-1.6$ & $<0.1-0.4$ \\
\hline Dihomo- $\gamma$-linolenic & $\mathrm{C} 20: 3(n-6)$ & $0.2-0.8$ & ND & ND \\
\hline Arachidonic & $\mathrm{C} 20: 4(n-6)$ & $0.3-0.8$ & ND & ND \\
\hline Docosahexaenoic & $\mathrm{C} 22: 6(n-3)$ & $0.1-0.5$ & ND & ND \\
\hline
\end{tabular}

* HM = human milk

$\uparrow$ SMA (Wyeth, UK) = Gold or White Cap formulas.

$\ddagger$ MIX $=$ Cow\&Gatc Premium (Cow\&Gate, UK-pre-1991 formula) or Farley’s (Heinz, UK) Ostermilk (pre-1991), Ostermilk 1 or Ostermilk 2 (both post 1991). $\S$ Infant details are given as means with standard deviations in parentheses.

I Milk fatty acid contents of the formulas (as weight percent of total fatty acids) represent manufacturers' published data confirmed by the authors and those for human milk are the authors' findings from a local population of mothers. ND $=$ not detected or $<0.05 \%$ of total fatty acids. 
Table 2. Profile of fatty acids in the term infant hepatic total lipid fraction in relation to diet

\begin{tabular}{|c|c|c|c|}
\hline \multirow[b]{2}{*}{ Diet } & \multicolumn{3}{|c|}{ Group } \\
\hline & 1 & 2 & 3 \\
\hline \multicolumn{4}{|l|}{ Lipid* } \\
\hline Recovery & $50.3(40.6-108.1)$ & $45.5(28.8-124.3)$ & $47.9 \quad(35.5-58.8)$ \\
\hline Cholesterol & $2.5(2.0-3.9)$ & $2.1 \quad(1.4-4.3)$ & $2.2(1.6-2.7)$ \\
\hline Triglyceride & $12.5(5.4-34.1)$ & $6.1 \quad(1.9-47.1)$ & $11.4(3.0-15.0)$ \\
\hline \multicolumn{4}{|l|}{ Fatty acid $\dagger$} \\
\hline C14:0 & $0.66(0.22-1.44)$ & $0.42(0.13-1.11)$ & $0.55(0.23-1.05)$ \\
\hline $\mathrm{C} 16: 0$ & $11.36(8.39-25.94)$ & $9.37(6.06-25.94)$ & $11.67(8.71-13.11)$ \\
\hline C16:1 $(n-7)$ & $0.91(0.36-2.58)$ & $0.47(0.29-2.24)$ & $0.83(0.34-0.98)$ \\
\hline $\mathrm{C} 18: 0$ & $4.40(3.68-7.13)$ & $4.36(2.92-7.32)$ & $3.73(2.60-4.44)$ \\
\hline C18:1 $(n-9)$ & $12.43(7.62-31.68)$ & $9.94(4.26-38.47)$ & $11.46(8.18-17.23)$ \\
\hline $\mathrm{C} 18: 2(n-6)$ & $6.03(3.77-11.63)$ & $6.89(4.49-19.48)$ & $5.37(4.32-7.86)$ \\
\hline $\mathrm{C} 18: 3(n-3)$ & $0.16(0.03-0.38) \ddagger$ & $0.17(0.04-1.07) \S$ & $0.02(0.01-0.15)$ \\
\hline \multicolumn{4}{|l|}{ LCPUFAף } \\
\hline $\mathrm{C} 20: 3(n-6)$ & $0.48(0.33-0.52)$ & $0.47(0.30-0.71)$ & $0.50(0.33-0.65)$ \\
\hline $\mathrm{C} 20: 4(n-6)$ & $3.05(2.83-4.09)$ & $2.58(1.90-3.43)$ & $2.36(1.75-2.65)$ \\
\hline $\mathrm{C} 22: 6(n-3)$ & $1.99(1.39-2.80)$ & $1.01(0.60-1.23)$ & $0.49(0.24-1.69)$ \\
\hline
\end{tabular}

All results are expressed as g per $\mathrm{kg}$ of tissue (wet weight) and given as medians and ranges.

* No between-group statistical analysis performed.

$\dagger$ Between group significances calculated by the two-tailed Mann-Whitney $U$ test.

$\ddagger p<0.01$, group 1 vs 3 .

$\S p<0.002$, group 2 vs 3 .

both AA and DHA exhibited age-dependent results' distributions, which were subjected to regression analysis and optimal curve fit (dependent on identifiable maxima and minima), computed by the Cricket Graph program (Computer Associates, San Diego, CA). The derived second (group 1) and third (groups 2 and 3 ) degree polynomials and calculated coefficients of determination $\left(r^{2}\right)$ are shown (Figs. 1 and 2).

The essential and nonessential fatty acid contents did not display a similar covariation with age (Minitab 10, Minitab Inc., PA) and were not normally distributed. Their group differences were therefore analyzed by the nonparametric, two-tailed Mann-Whitney $U$ test with significance levels set at

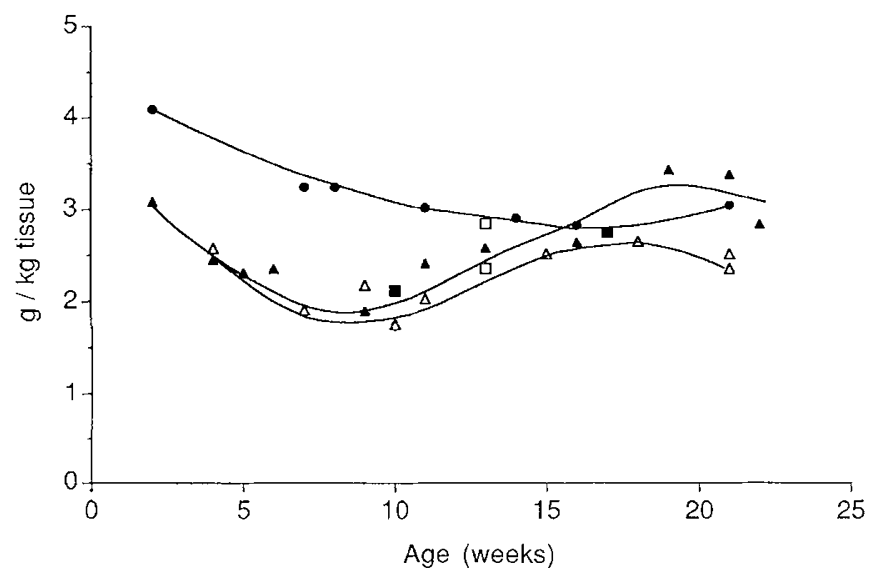

Figure 1. Hepatic total lipid AA $[\mathrm{C} 20: 4(n-6)]$ in relation to infants' diet and age. AA contents for a given age $(x)$ are defined by the following polynomial equations.

Group $1=4.448-0.206 x+0.0067 x^{2} ; r^{2}=0.99$

Group $2=4.123-0.604 x+0.0542 x^{2}-0.00131 x^{3} ; r^{2}=0.84$

Group $3=4.740-0.784 x+0.0675 x^{2}-0.00168 x^{3} ; r^{2}=0.84$

with $\mathrm{C} 20: 4(n-6)$ contents in $\mathrm{g} / \mathrm{kg}$ wet tissue and $x$ in weeks. $\boldsymbol{\bullet}$, Group $1 ; \boldsymbol{\Delta}$, group $2 ; \triangle$, group $3 ; \mathbf{\square}$, preterm-group $2 ; \square$, preterm-group 3 . $p<0.01$ inasmuch as multigroup comparison was undertaken. The small number of observations $(n=4)$ on preterm infants and their absence from the breast-fed group precluded between group statistical analysis; however, visual interpretation of their LCPUFA results with respect to the corresponding term individuals was made.

\section{RESULTS}

The results of the hepatic total lipid fatty acid analyses are best subdivided into three categories, namely the nonessential (saturated and mono-unsaturated), the essential (linoleic and $\alpha$-linolenic), and their LCPUFA derivatives. There were no significant differences between feeding groups in the nonessential fatty acids (Table 2). The hepatic essential fatty acid, $\alpha$-linolenic, content was significantly lower in group 3 than in both groups $1(p<0.01)$ and $2(p<0.002)$. In general, human milk-fed infants had greater concentrations of the LCPUFA AA and DHA than those fed either of the formula diets, with results' ranges (Table 2) and distributions illustrated (Figs. 1 and 2). Hepatic AA content in group 1 nevertheless fell gradually over the 5 -mo period from 4 to $3 \mathrm{~g} / \mathrm{kg}$ tissue (Fig. 1). Polynomial equations demonstrated that both formula groups had minimal liver AA content ( $2 \mathrm{~g} / \mathrm{kg}$ tissue) in the third month of life $(8-10 \mathrm{wk})$ with a subsequent rapid increase. The curves for groups 1 and 2 intersected at $16 \mathrm{wk}$ and those of groups 1 and 3 became tangential at approximately $18 \mathrm{wk}$ before again diverging. In comparison with breast-fed infant liver the reduction in absolute amounts of AA in the liver of formula-fed infants throughout the first months of life was on average approximately $1 \mathrm{~g} / \mathrm{kg}$ tissue or approximately $0.15-0.20 \mathrm{~g} \mathrm{AA}$ per liver. No obvious differences were evident in AA concentrations between term and preterm infants of similar chronologic age.

Although the pattern of results for hepatic DHA (Fig. 2) was similar to that found for AA, with the minima for the formula 


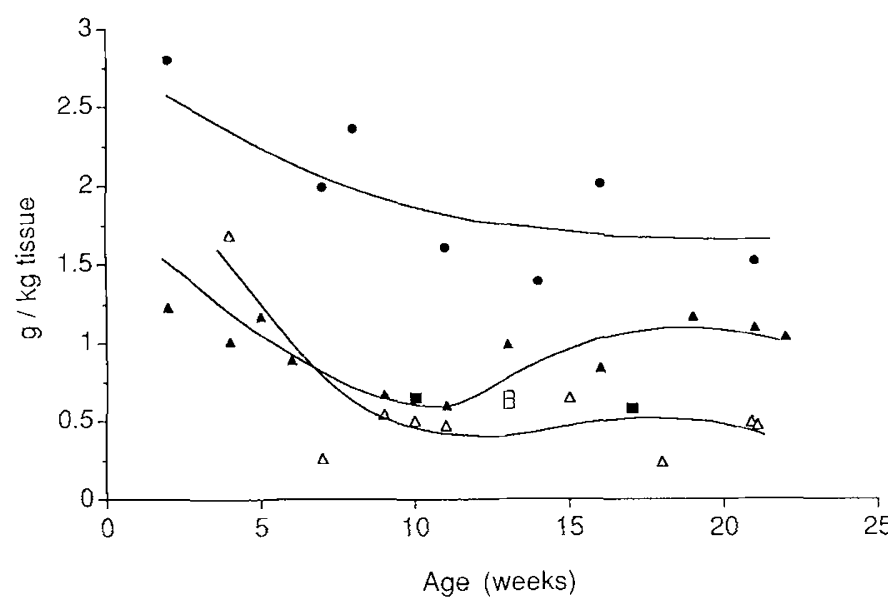

Figure 2. Hepatic total lipid DHA [C22:6(n-3)] in relation to infants' diet and age. DHA contents for a given age $(x)$ are defined by the following polynomial equations.

Group $1=3.105-0.168 x+0.0046 x^{2} ; r^{2}=0.73$

Group $2=1.688-0.221 x+0.0163 x^{2}-0.00034 x^{3} ; r^{2}=0.63$

Group $3=3.872-0.791 x+0.0573 x^{2}-0.00131 x^{3} ; r^{2}=0.74$

with $\mathrm{C} 22: 6(n-3)$ contents in $\mathrm{g} / \mathrm{kg}$ wet tissue and $x$ in weeks. Symbols as in Figure 1.

groups 2 and 3 again coincident during the third month, the major differences were that the human milk fed compositions were more randomly distributed, and in group 3 no increase in liver DHA concentrations was detected at the end of the third month such that the reduction with respect to the group 1 infants at $21 \mathrm{wk}$ was still of the order of $1 \mathrm{~g} / \mathrm{kg}$ tissue (Fig. 2). In group 2 an increase in DHA levels in the older infants $(>12$ wk) was apparent (Fig. 2) but they did not impinge on the group 1 curve at any stage. The hepatic DHA compositions of the preterm infants were not substantially different from their term counterparts, although there was no evidence of an increase in DHA in the 17-wk-old infant of $32 \mathrm{wk}$ of gestation. No significant differences were found between the results of the duplicate tissue analyses nor in those reassayed after long-term (up to $12 \mathrm{mo}$ ) storage.

\section{DISCUSSION}

At first sight it may seem impossible to unravel and evaluate the many individual contributions toward hepatic fatty acid concentrations in early life. To reduce the complications in such a process we sought to ensure that our experimental procedures would estimate total fatty acids derived from the three major lipid components, the phospholipids, triglycerides, and cholesterol esters. Hepatic metabolism of these fatty acids involves several cell organelles, initially mitochondrial synthesis from malonyl and acetyl CoA or breakdown by $\beta$-oxidation predominantly confined to the nonessential saturated and mono-unsaturated fatty acids and specific for those up to a 16-carbon chain length (palmitic acid).

From Tables 1 and 2, it can be seen that there is a degree of correlation between the levels of hepatic and dietary nonessential fatty acids. Similarly it was probably to be expected that the essential fatty acids, linoleic and $\alpha$-linolenic, would reflect dietary intake (Table 2); however, although they themselves contribute little to neuronal structures $(19,20)$, they are of critical importance as substrates in the hepatic synthesis of the LCPUFA AA and DHA, respectively. Formerly thought to be restricted to the microsomes, new evidence suggests that synthesis of DHA also has a peroxisomal component (21). Some evaluation of the individual contributions toward the AA and DHA age-related distributions may be possible. The universal reduction in these LCPUFA in the first weeks of life (Figs. 1 and 2) possibly represents the cumulative effects of both dilution through tissue growth and maturation and some degree of mobilization from the adipose and endogenous hepatic stores. Easier to delineate could be that of dietary input, which during our study was confined to those infants receiving human milk and may be reflected in the differences between the corresponding group curves (Figs. 1 and 2).

The contributions to liver AA and DHA contents provided by enzymatic desaturation and elongation of the essential fatty acids would in normal circumstances be the most difficult to differentiate. However, even with what appears a wholly inadequate provision of $\alpha$-linolenic acid precursor in the third diet, it was observed that both formula group curves for DHA were virtually superimposable during the first 3 mo of life (Fig. 2). This may indicate an absence or reduced supply of synthetic DHA to the infants in these formula groups. Subsequently there appears to be evidence of a relative increase in the hepatic DHA of group 2 compared with group 3 (Fig. 2). It may be that only after approximately $12 \mathrm{wk}$ is optimal hepatic synthesis of DHA evinced and that irrespective of dietary provision of $\alpha$-linolenic acid, $\Delta 4$-desaturation is poorly or nonfunctioning in early life. This appears to corroborate recent observations on cord plasma fatty acids which seem to demonstrate that $\Delta 4$ desaturation and not $\Delta 6$ or $\Delta 5$ may be rate-limiting in the formation of hepatic DHA (22). If as indicated $\Delta 4$-desaturation is achieved through microsomal chain elongation of docosapentaenoic acid [C22:5(n-3)] followed by $\Delta 6$-desaturation then the final peroxisomal $\beta$-oxidation may be the true rate-limiting step to DHA production in the infant liver (21). This has profound consequences for the supply of essential fatty acids and their LCPUFA derivatives to infants in the immediate postnatal period when brain growth and development are most vulnerable to reduced provision of these fatty acids. As we have now established that subcutaneous tissue reserves are insufficient (2) and hepatic $\Delta 4$-desaturation probably at best suboptimal, we again emphasize the need of dietary DHA for all formula-fed infants. It would appear that from the fourth month onward some conversion of $\alpha$-linolenic acid to DHA occurs when the substrate is present in sufficient concentration such that synthetic DHA may represent approximately $0.6 \mathrm{~g} / \mathrm{kg}$ tissue in the liver at 5 mo (Fig. 2). Within the human milk-fed group DHA results, that of the 16-wk-old infant at first appeared to be an outlier until it was recognized that uniquely this infant exhibited a subcutaneous tissue $\alpha$-linolenic acid concentration similar to that of an SMA-fed infant (2). This hepatic DHA composition (Fig. 2) may correspond to the summation of both a dietary and synthetic component.

From Figure 1 the age-related distributions of AA can be seen. However, the minimum levels, which as with DHA occur simultaneously at 8-10 wk in both formula-fed groups, repre- 
sent amounts which at approximately $2 \mathrm{~g} / \mathrm{kg}$ tissue are four times greater than that for DHA. It seems that in term infants no prolonged reduction in hepatic $\mathrm{AA}$ is present perhaps as no peroxisomal $\beta$-oxidation stage is required in its formation (only $\Delta 6$ - and $\Delta 5$-desaturation), and indeed formula-fed infants have the capacity to incorporate increased amounts of AA (and other $n-6$ series LCPUFA) into neural membranes in apparent response to reduced DHA supply (1). This may be explained further by the contrast with the DHA distribution curves, which for the formula-fed groups at no point intersect that of the human milk-fed group, whereas those for AA are at least equivalent by $16 \mathrm{wk}$ and that of group 2 for a period ultimately in excess of group 1 concentrations (Fig. 1).

The AA results for the preterm infants all lie close to their corresponding term group curves (Fig. 1), indicating that their $\Delta 6$ - and $\Delta 5$-desaturase enzymes may also be relatively active in the first weeks of life. The preterm infant appears to possess enzyme activities that are appropriate to chronologic age but liver growth and development related to gestational age, therefore although their LCPUFA production per $\mathrm{kg}$ of tissue is similar to that of term infants of the same age, the total hepatic content of LCPUFA in preterm infants of gestational ages from 30 to $33 \mathrm{wk}$ are on average $20-30 \%$ lower. Nonetheless, as it is present in breast milk, it would seem prudent to provide dietary AA to all formula-fed infants in the first 4 mo of life.

In summary, although use of necropsy material necessarily precludes investigation of the dynamics of the processes involved in hepatic fatty acid metabolism, nevertheless we believe that we have clearly demonstrated that reliance on hepatic peroxisomal (or microsomal) synthesis of DHA in the first months of life has been misplaced. With formula milks we would advise that they should contain the range of LCPUFA found in human milk if neonatal neurologic and cardiovascular structural and possibly functional integrity is not to be compromised.

Acknowledgments. The authors thank Myra Fergusson and Jean Hyslop for their assistance in the preparation of this manuscript.

\section{REFERENCES}

1. Farquharson J, Cockburn F, Patrick WA, Jamieson EC, Logan RW 1992 Infant cerebral cortex phospholipid fatty acid composition and diet. Lancet 340:810-813

2. Farquharson J, Cockburn F, Patrick WA, Jamieson EC, Logan RW 1993 Effect of diet on infant subcutaneous tissue triglyceride fatty acids. Arch Dis Child 69:589 593

3. Crawford MA 1993 The role of essential fatty acids in neural development: implications for perinatal nutrition. Am J Clin Nutr 57(suppl 5):703S-710S

4. Neuringer M, Connor WE 1986 Omega-3 fatty acids in brain and retina: evidence for their essentiality. Nutr Rev 44:285-294

5. Neuringer M, Anderson GJ, Connor WE 1988 The essentiality of n-3 fatty acids for development and function of retina and brain. Annu Rev Nutr 8:517-541

6. Hassam AG, Sinclair AJ, Crawford MA 1975 The incorporation of orally fed radioactive $\gamma$-linolenic acid and linoleic acid into the liver and brain lipids of suckling rats. Lipids 10:417-420

7. Poisson JP, Dupuy RP, Sarda P, Descomps B, Narce M, Rieu D, Crastes de Paulet A 1993 Evidence that liver microsomes of human neonates desaturate essential fatty acids. Biochim Biophys Acta 1167:109-113

8. El Boustani S, Causse JE, Descomps B, Monnier L, Mendy F, Crastes de Paulet A 1989 Direct in vivo characterization of delta 5 desaturase activity in humans by deuterium labeling: Effect of insulin. Metabolism 38:315-321

9. Kirstein D, Hoy CE, Holmer G 1983 Effect of dietary fats on the $\Delta 6$ and $\Delta 5$ desaturation of fatty acids in rat liver microsomes. Br J Nutr 50:749-756

10. Bourre JM, Piciotti M 1992 Delta-6 desaturation of alpha-linolenic acid in brain and liver during development and aging in the mouse. Neurosci Lett 141:65-68

11. Fujiwara $Y$, Okayasu $T$, Ishibashi T, Imai $Y 1983$ Immunochemical evidence for the enzymatic difference of $\Delta 6$-desaturase from $\Delta 9$ and $\Delta 5$-desaturase in rat liver microsomes. Biochem Biophys Res Commun 110:36-40

12. Crawford MA, Casperd NM, Sinclair AJ 1976 The long-chain metabolites of linoleic and linolenic acids in liver and brain in herbivores and carnivores. Comp Biochem Physiol 54B:395-401

13. Martinez M 1992 Tissue levels of polyunsaturated fatty acids during early human development. J Pediatr 120(suppl):S129-S138

14. Clandinin MT, Chappell JE, Heim T 1981 Do low weight infants require nutrition with chain elongation-desaturation products of essential fatty acids? Prog Lipid Res 20:901-904

15. Sinclair AJ 1975 The incorporation of radioactive polyunsaturated fatty acids into the liver and brain of the developing rat. Lipids 10:175-184

16. Farquharson J 1994 Infant cerbral cortex and dietary fatty acids. Eur J Clin Nutr 48(suppl 2):24-26

17. Clandinin MT Chappell JE, Leong S, Heim T, Swyer PR, Chance GW 1980 Extrauterine fatty acid accretion in infant brain: Implications for fatty acid requirements. Early Hum Dev 4:131-138

18. Farquharson J, Jamieson EC, Berry E, Sutton A, Logan RW 1988 Combined enzymatic assay of phosphatidylglycerol and phosphatidylcholine in amniotic fluid. Clin Chim Acta 171:175-186

19. O'Brien JS, Fillerup DL, Mead JF 1964 Quantification and fatty acid and fatty aldehyde composition of ethanolamine, choline and serine phosphoglycerides in human cerebral gray and white matter. J Lipid Res 5:329-338

20. Svennerholm L 1968 Distribution and fatty acid composition of phosphoglycerides in normal human brain. $\boldsymbol{J}$ Lipid Res 9:570-578

21. Voss A, Reinhart M, Sankarappa S, Sprecher H 1991 The metabolism of $7,10,13,16,19$-docosapentaenoic acid to $4,7,10,13,16,19$-docosahexaenoic acid in rat liver is independent of a 4-desaturase. J Biol Chem 266:19995-20000

22. Hoving EB, van Beusekom CM, Nijeboer HJ, Muskiet FAJ 1994 Gestational age dependency of essential fatty acids in cord plasma cholesterol esters and triglycerides. Pediatr Res 35:461-469 